\title{
Reproductive History and Risk of Nasopharyngeal Carcinoma: A Population-Based Case-Control Study in Southern China
}

\author{
Ruimei Feng ${ }^{1,2}$, Ellen T. Chang ${ }^{3,4}$, Zhiwei Liu ${ }^{5}$, Qing Liü ${ }^{1,2}$, Yonglin Cai ${ }^{6,7}$, Zhe Zhang ${ }^{8,9}$, \\ Guomin Chen ${ }^{10}$, Qi-Hong Huang ${ }^{11}$, Shang-Hang Xie ${ }^{1,2}$, Su-Mei Cao ${ }^{1,2}$, Yu Zhang ${ }^{2}$, Jingping \\ Yun $^{2}$, Wei-Hua Jia ${ }^{2}$, Yuming Zheng ${ }^{6,7}$, Jian Liao ${ }^{12}$, Yufeng Chen ${ }^{5}$, Longde Lin ${ }^{9}$, Ingemar \\ Ernberg $^{13}$, Guangwu Huang ${ }^{\# 8,9}$, Yi Zeng ${ }^{\# 10}$, Yi-Xin Zeng ${ }^{\# 2,14}$, Hans-Olov Adami ${ }^{\# 5,15}$, and \\ Weimin Ye $\# 1,2,5,{ }^{*}$ \\ 1. Department of Cancer Prevention Center, Sun Yat-sen University Cancer Center, Guangzhou, \\ China
}

2. State Key Laboratory of Oncology in South China \& Collaborative Innovation Center for Cancer Medicine \& Guangdong Key Laboratory of Nasopharyngeal Carcinoma Diagnosis and Therapy, Sun Yat-sen University Cancer Center, Guangzhou 510060, China

3.Exponent, Inc., Health Sciences Practice, Menlo Park, CA, USA

4. Stanford Cancer Institute, Stanford, CA, USA

5.Department of Medical Epidemiology and Biostatistics, Karolinska Institutet, Stockholm, Sweden

6.Department of Clinical Laboratory, Wuzhou Red Cross Hospital, Wuzhou, China

7.Wuzhou Health System Key Laboratory for Nasopharyngeal Carcinoma Etiology and Molecular Mechanism, Wuzhou, China

8.Department of Otolaryngology-Head \& Neck Surgery, First Affiliated Hospital of Guangxi Medical University, Nanning, China

9. Key Laboratory of High-Incidence-Tumor Prevention \& Treatment (Guangxi Medical University), Ministry of Education, Nanning, China

10. State Key Laboratory for Infectious Diseases Prevention and Control, Institute for Viral Disease Control and Prevention, Chinese Center for Disease Control and Prevention, Beijing, China

11. Sihui Cancer Institute, Sihui, China

12. Cangwu Institute for Nasopharyngeal Carcinoma Control and Prevention, Wuzhou, China

13.Department of Microbiology, Tumor and Cell Biology, Karolinska Institutet, Stockholm, Sweden

14.Beijing Hospital, Beijing, China

\footnotetext{
"Correspondence to: Weimin Ye, MD, PhD, Department of Cancer Prevention Center, Sun Yat-sen University Cancer Center, Guangzhou, China; +86-020-87345682, Fax: +86-020-87343392, yewm@sysucc.org.cn.

Publisher's Disclaimer: This is a PDF file of an unedited manuscript that has been accepted for publication. As a service to our customers we are providing this early version of the manuscript. The manuscript will undergo copyediting, typesetting, and review of the resulting proof before it is published in its final citable form. Please note that during the production process errors may be discovered which could affect the content, and all legal disclaimers that apply to the journal pertain.

Conflict of interest: none declared.
} 
15.Department of Epidemiology, Harvard TH Chan School of Public Health, Boston, MA, USA

\# These authors contributed equally to this work.

\section{Abstract}

Objects—Nasopharyngeal carcinoma (NPC) incidence exhibits a remarkable sex disparity, with higher risk among males. Whether this pattern can be partly explained by female reproductive history is unclear.

Methods-A population-based case-control study of NPC was conducted in southern China between 2010 and 2014, including 674 histopathologically verified female NPC cases and 690 female controls randomly selected from population-based registries. Odds ratios (ORs) and 95\% confidence intervals (CIs) were estimated using logistic regression after adjusting for potential confounders.

Results-Women who had 3, 4, or $\geq 5$ pregnancies compared with 2 pregnancies were at significantly increased risk for NPC (ORs1.56, 1.45 and 1.88, respectively). History of deliveries was similarly associated with a greater risk of NPC. These positive associations were more prominent in women who were younger than 50 years, had less than 10 years of education, or were white-collar workers. Increasing time since menopause was associated with a diminished NPC risk $\left(P_{\text {trend }}=0.010\right)$. Women more than 15 years after menopause had a 0.35 -fold $(95 \% \mathrm{CI}$ : 0.16-0.75) NPC risk compared with those $0-3$ years after menopause.

Conclusion-Contrary to our hypothesis, a history of pregnancy or delivery increased the risk of NPC and the risk decreased with increasing time since menopause. However, the non-linear relationship and no consistent risk patterns across strata indicate that the observed associations are unlikely to be causal, and may at least partially be ascribed to residual confounding by socioeconomic factors.

\section{Keywords}

Pregnancy; Menopause; Intrinsic hormone exposure; Nasopharyngeal carcinoma; Case-control study; Southern China

\section{Introduction}

Nasopharyngeal carcinoma (NPC) incidence is higher in males than females across the world, especially in endemic areas. Age-standardized (Segi-Doll world standard) NPC incidence rates (per 100,000) in males were indeed 2- to 3-fold higher than those in females in 2012 in North Africa (2.3 vs. 1.0), Europe (0.6 vs. 0.2), East Asia (2.5 vs. 1.0), Hong Kong (12.8 vs. 4.0), Shanghai, China (3.1 vs. 1.0), and Zhongshan, China (25.0 vs. 7.7) ${ }^{[1] .}$

The mechanisms responsible for the sex disparity in NPC incidence remain unclear. Recent studies suggest that genetics or environmental exposures may contribute to this pattern. In particular, some studies reported that the sex difference was related to differential genetic susceptibility, with a hypothesis that the $\mathrm{X}$ chromosome or a sex-based difference in gene expression, perhaps interacting with Epstein-Barr virus (EBV) infection, was involved in the development of NPC ${ }^{[2-4]}$. Other studies attributed the sex disparity to environmental factors 
that are unevenly distributed between females and males, such as smoking and certain occupational exposures ${ }^{[5,6]}$. Another contributing cause may be differences in levels of sex steroid hormones ${ }^{[7-10]}$.

In line with the female hormone-related theory, we hypothesized that certain female reproductive characteristics may confer protection against NPC risk. To date, few epidemiological studies of NPC have focused on risk factors among females ${ }^{[11-13]}$, and no association has been established between female reproductive factors and risk of NPC. Therefore, we aimed to investigate the relationship between female reproductive history, including pregnancy and menopause-related factors, and NPC risk in a large, populationbased case-control study in southern China.

\section{Materials and methods}

\section{Study population}

We conducted a collaborative study entitled "NPC Genes, Environment, and EBV" (NPCGEE) in three areas from Guangdong Province and Guangxi Autonomous Region of southern China between 2010 and 2014. Study details have been described previously ${ }^{[14-16]}$. All histopathologically diagnosed incident cases of NPC, enrolled from 10 hospitals and 2 cancer research institutions, were ascertained by a rapid report system. Control subjects, frequency matched to the 5-year age and sex distributions of cases, were randomly selected from the dynamic total population registries. Eligible participants were those aged 20 to 74 years, living in the study area during the recruitment period, and with no previous malignant disease or congenital or acquired immunodeficiency.

The overall participation rates were $83.2 \%$ for cases and $82.7 \%$ for controls. Among cases, 679 were female (26.6\%), and for controls $691(26.1 \%)$. Women with missing information on pregnancy history and menopausal status $(\mathrm{N}=3)$ or with poor-quality data $(\mathrm{N}=3)$ were excluded, thus leaving 674 cases and 690 controls for the final analysis.

Institutional review boards or ethics boards from all study centers approved this study. Eligible subjects granted written or oral informed consent prior to participation.

\section{Data collection}

Data on lifestyle and other potential NPC risk factors, including reproductive history, were collected using a structured electronic questionnaire during in-person interviews conducted by trained interviewers. Women reported whether they had ever been pregnant, and if so, the total number of pregnancies, age at first pregnancy, the outcome of the first pregnancy, and the total number of deliveries (including stillbirths). Women also reported their menopausal status, and for postmenopausal women, age at menopause was recorded.

\section{Statistical analysis}

The distribution of the number of deliveries $(0,1,2,3,4$ or 25$)$ across demographics and potential confounding factors among study subjects were presented using proportions. Difference of these characteristic factors between female cases and controls were also compared using Chi-square test. Associations between reproductive factors and NPC risk 
were evaluated using unconditional logistic regression models, from which odds ratios (ORs) and corresponding 95\% confidence intervals (CIs) were derived.

The pregnancy-related factors included ever pregnancy (yes or no) and, for ever-pregnant women, number of pregnancies $(1,2,3,4$, or $\geq 5)$, age at first pregnancy ( $₫ 20,21-25,26-29$, or $\geq 30$ years), outcome of first pregnancy (natural delivery, stillbirth, abortion, or other), and number of deliveries $(1,2,3,4$, or $\geq 5)$. The menopause-related factors included menopausal status (yes or no) and, for peri- or postmenopausal women, age at menopause ( $\leq 47,48-49$, $50-51$, or $\geq 52$ years). Cut-off values for age at first pregnancy and age at menopause were set at approximate quartiles among controls.

Potential confounders were considered according to prior knowledge and associations with NPC risk in this study. These included age (in 10-year groups), area of residence (Zhaoqing, Wuhzou, or Guiping/Pingnan), education level (0,1-6, 7-9, or $\geq 10$ years), current housing type (building (concrete structure) or cottage (clay brick structure)/boat), current occupation (unemployed, farmer, blue-collar, white-collar, or other/unknown), cigarette smoking (ever or never), current tea drinking (yes or no), salt-preserved fish consumption in 2000-2002 (yearly or less, monthly, or weekly or more), body mass index (<18.5, 18.5-22.9 or $\geq 23.0$ $\mathrm{kg} / \mathrm{m}^{2}$ ) and first-degree family history of NPC (yes, no, or unknown). Minimally adjusted ORs were adjusted for the frequency matching factors, i.e., age and area of residence. Multivariate adjusted ORs were additionally adjusted for other potential confounders listed in Table 1, except for cigarette smoking, because women rarely smoked in our study population.

To investigate potential effect modification in relation to number of deliveries $(1,2,3$, 4, or $\geq 5)$, stratified analyses were further conducted by age ( $<50$ or $\geq 50$ years) and the three proxy indicators of socioeconomic status (SES), including education level ( $<10$ or $\geq 10$ years), current occupation (unemployed/farmer/blue-collar or white-collar) and current housing type (building (concrete structure) or cottage (clay brick structure)/boat).

Analyses were performed with SAS version 9.4 (SAS Institute). The two-sided significance level for all statistical tests was 0.05 .

\section{Results}

\section{Baseline characteristics of study subjects}

Table 1 presents baseline characteristics of the 1,364 study subjects ( 674 female cases and 690 controls) stratified by number of deliveries. Women having more deliveries were more likely to reside in the Guiping/Pingnan area, to be older at diagnosis/interview, to have a lower education level, to live in a cottage (clay brick structure)/boat, to be unemployed or a farmer, to be a nondrinker of tea, to be overweight at age 20 , and to have consumed more salt-preserved fish between 2000 and 2002. Baseline characteristics for cases and controls are separately presented in the Supplementary Table 1. Cases tended to have a lower education level, to live in a cottage (clay brick structure)/boat, to be blue-collar workers, to be less likely tea drinkers, to be overweight at age 20 , and to more likely have a family history of NPC. 


\section{Risk of NPC in relation to pregnancy history}

Table 2 shows the ORs and 95\% CIs for the associations between pregnancy-related factors and risk of NPC. Compared with women who had ever been pregnant, women who had never been pregnant had no significantly increased risk of NPC (fully adjusted OR: 2.16, 95\% CI: 0.94-4.94).

The number of pregnancies or deliveries showed a non-linear relationship with NPC risk. Most associations in the minimally adjusted models (adjusted for age and area of residence) were attenuated after fully adjusting for other confounders. Compared with women who had two pregnancies (the most common number among controls), having had one pregnancy was associated with a non-significant increased risk of NPC (fully adjusted OR: 1.43, 95\% CI: $0.89-2.27$ ), while those having had 3, 4, or $\geq 5$ pregnancies had $56 \%, 45 \%$ and $88 \%$ excess risks of NPC, respectively. Having had one versus two deliveries was significantly associated with NPC risk (fully adjusted OR: 1.65, 95\% CI: 1.11-2.46), while having had more than 3,4 , or $\geq 5$ deliveries was associated with $60 \%, 36 \%$ and $70 \%$ excess risks of NPC, respectively.

Having first been pregnant at age $\_20,26-29$ or $\geq 30$ years compared with age 21-25 years was not significantly associated with risk of NPC. Similarly, no significant relationship was found between outcome of the first pregnancy and risk of NPC.

\section{Risk of NPC in relation to menopausal history}

Table 3 displays the associations between menopause-related factors and risk of NPC. Associations did not differ substantially between the minimally adjusted models (adjusted for age and area of residence) and fully adjusted models. Compared with premenopausal women, peri- and postmenopausal women had a slightly, non-significantly increased risk for NPC. Compared with premenopausal women, postmenopausal women exhibited a generally increasing trend in NPC risk with later age at menopause, from less than 48 years to more than 51 years $\left(P_{\text {trend }}=0.06\right.$, fully adjusted model $)$. NPC risk was not significantly elevated for women who entered menopause at $\geq 52$ years, with an adjusted OR of 1.67 (95\% CI: 0.96-2.89). Among peri-/postmenopausal women, increasing time since menopause was associated with a decreasing trend in NPC risk ( $P_{\text {trend }}=0.01$, fully adjusted model). In particular, women who experienced menopause at least 15 years previously had a 0.35 -fold (95\% CI:0.16-0.75) risk of NPC compared with women 0 to 3 years after menopause. The results were similar after further adjusting for age at menopause (data now shown).

\section{Risk of NPC stratified by age and socioeconomic status}

Table 4 reports the associations between number of pregnancies or deliveries and the risk of NPC stratified by age at diagnosis/interview ( $<50$ years vs. 250 years). For women younger than 50 years, both one pregnancy and more than two pregnancies were associated with higher risks of NPC compared with two pregnancies; adjusted ORs were 1.98 (95\% CI: 1.17-3.37) for one pregnancy and 2.00 (95\% CI:1.33-3.00), 1.89 (95\% CI: 1.16-3.07), and 2.15 (95\%CI: 1.32-3.50), for 3, 4 or $\geq 5$ pregnancies, respectively. Similar results were shown for number of deliveries, although point estimates were always lower. By contrast, no 
significant associations were observed among women $\geq 50$ years, for either number of pregnancies or deliveries.

Figure 1 presents results from stratified analyses by three SES indicators (education level, current occupation, or current housing type). Significantly higher risk of NPC in association with one delivery was found among women who had less than 10 years of education, were unemployed/farmers/blue-collar workers, or resided in a cottage (clay brick structure)/boat (Figure 1. a), while no significant association between one delivery and NPC risk was shown among women who had more than 10 years of education or were white-collar workers (Figure 1. b). Socioeconomic heterogeneity in the association of NPC risk with more than two deliveries was less marked, but generally stronger positive associations were noted among women with less education or lower occupational status.

\section{Discussion}

To our knowledge, this is the first study to systematically evaluate possible associations between female reproductive factors and the risk of NPC. We found borderline significant positive associations between an increasing number of pregnancies or deliveries, later age at menopause, and more recent menopause and risk of NPC. However, the positive associations with number of pregnancies or deliveries were only observed in women who were younger than 50 years, had less than 10 years of education or were non-white-collar workers.

A non-linear relationship with NPC risk in association with number of pregnancies or deliveries was shown in our study. Women who had only one pregnancy or delivery showed a higher risk of NPC than women with two pregnancies or deliveries. Similarly, women experiencing more than two pregnancies or deliveries had excess risk of NPC, although with no dose-response pattern. The Chinese traditional culture, in which women with relatively poor socioeconomic status are prone to bear more than one baby, might confound associations between reproductive history and NPC risk in at least two ways. First, China's one-child policy, implemented in 1980, probably affected the reproductive experience, particularly among those of more recent birth cohorts, well-educated, and white-collar workers, because of financial and employment-based penalties for persons with more than one child. Second, women in poorer physical health may be less likely to have more than one child. The distribution of pregnancy or delivery in our study also confirmed that women with multiple pregnancies were more likely to have a low profile of SES and belong to more recent birth cohorts.

Given all of the above considerations, we conducted analyses stratified by age ( $<50$ or $\geq 50$ years) and three different socioeconomic indicators. Women older than 50 years were born before 1960s and therefore less likely to be influenced by the one-child policy. Similarly, women with more than 10 years of education or being white-collar workers were more likely to work in government agencies, and then more likely to be influenced by one-child policy. The stratified analyses also indicated that the positive associations between multiple pregnancies or deliveries and NPC risk were mostly observed in women younger than 50 years, who had a lower education level or were non-white-collar workers. Therefore, the increased risk of NPC following multiple pregnancies may partly be ascribed to lower 
socioeconomic status. However, other potential explanations cannot be excluded, such greater risk of EBV reactivation and consequent NPC risk among women with multiple pregnancies, since the immune system appears to be down-regulated during pregnancy ${ }^{[17-20]}$. Some studies reported that EBV reactivation was enhanced among pregnant women[17, 18, 21, 22], but others reported no association[23, 24].

Intrinsic hormone exposures may also contibute to the observed sex difference in NPC incidence. The decrease in risk of NPC with time since menopause occurs in concert with a drastic decline in estrogen levels. A study of NPC incidence in Hong Kong in 1983-2008 ${ }^{[25]}$ showed a delayed peak in NPC incidence among females at ages 55-59 years, compared a peak at ages 50-54 years among males, followed by a decline at older ages in both sexes. The authors speculated that a protective effect of estrogen might explain this discrepancy, as estrogen can inhibit NPC cell growth mediated by estrogen receptors identified in the tissues ${ }^{[7]}$. Similarly, another study in China reported an NPC incidence peak at 55-59 years, followed by a decline in both sexes ${ }^{[26]}$. A protective effect of estrogen may explain the sex difference in NPC incidence, but the observed decreasing trend in NPC risk after menopause contradicts a causal association.

The major strengths of our study are the strictly population-based design, large size, high participation rates among both cases and controls, and detailed collection of high-quality data. However, our study also has some disadvantages. First, the sample size was relatively limited for some further stratified analyses. Second, reproductive hormone levels were not measured, nor were potential clues to biological mechanism, such as EBV load. However, the number of deliveries and menopausal status are well validated indicators of relative levels of long-term female reproductive hormones, which fluctuate substantially within individuals over short periods of time and are therefore difficult to be measured reliably in epidemiologic studies. Exogenous influences on female reproductive hormone levels, such as oral contraceptives and hormone replacement therapy - without any established association with NPC risk - are little used in China, especially in rural areas ${ }^{[27]}$ and therefore unlikely to confound our risk estimates.

In conclusion, although we observed excess risk of NPC in association with one pregnancy or delivery and more than two pregnancies or deliveries, compared with two pregnancies or deliveries, the non-linear relationship and lack of consistent risk patterns across birth cohorts or SES strata indicate that the observed positive associations might be ascribed to socioeconomic status and other unknown confounding factors.

\section{Supplementary Material}

Refer to Web version on PubMed Central for supplementary material.

\section{Acknowledgments}

We thank the members of the External Advisory Board of the NPC Genes, Environment, and Epstein-Barr Virus Study, including Dr. Curtis Harris (US National Cancer Institute), Dr. Mary-Claire King (University of Washington), Dr. Xihong Lin (Harvard T.H. Chan School of Public Health), Dr. Wei-Cheng You (Peking University) and Dr. You-Lin Qiao (Chinese Academy of Medical Sciences) for their guidance of the overall casecontrol study. 
The content of this article is solely the responsibility of the authors and does not necessarily represent the official views of the funding agencies.

Role of the funding source

The content is solely the responsibility of the authors and does not necessarily represent the official views of the funding agencies.

\section{References}

[1]. Bray FCMML, Piñeros M, Znaor A, Zanetti R and Ferlay J, Cancer Incidence in Five Continents, Vol. XI (electronic version). In: 2017, editor. http://ci5.iarc.fr ed: Lyon: International Agency for Research on Cancer.

[2]. Wee JTS, Ha TC, Loong SLE, Qian CN. Is nasopharyngeal cancer really a "Cantonese cancer"? Chin J Cancer 2010;29:517. [PubMed: 20426903]

[3]. Simons MJ. Nasopharyngeal carcinoma as a paradigm of cancer genetics. Chin J Cancer 2011;30:79. [PubMed: 21272439]

[4]. Tian W, Zeng XM, Li LX, Jin HK, Luo QZ, Wang F, et al. Gender-specific associations between MICA-STR and nasopharyngeal carcinoma in a southern Chinese Han population. Immunogenetics 2006;58:113-21. [PubMed: 16547745]

[5]. Yuan JM, Wang XL, Xiang YB, Gao YT, Ross RK, Yu MC. Non-dietary risk factors for nasopharyngeal carcinoma in Shanghai, China. International Journal of Cancer 2000;85:364. [PubMed: 10652428]

[6]. Cheng YJ, Hildesheim A, Hsu MM, Chen I, Brinton LA, Levine PH, et al. Cigarette smoking, alcohol consumption and risk of nasopharyngeal carcinoma in Taiwan. Cancer Causes \& Control 1999;10:201-7. [PubMed: 10454065]

[7]. Zheng TR, Li JC, Liu XY. The Study of Estrogen and Progesterone Receptor in Nasopharyngeal Carcinoma. Chinese Journal of Cancer Research 1996;8:64-6.

[8]. Steffan RJ, Matelan E, Ashwell MA, Moore WJ, Solvibile WR, Trybulski E, et al. Control of chronic inflammation with pathway selective estrogen receptor ligands. Current Topics in Medicinal Chemistry 2006;6:103-11. [PubMed: 16454762]

[9]. Naugler WE, Sakurai T, Kim S, Maeda S, Kim K, Elsharkawy AM, et al. Gender disparity in liver cancer due to sex differences in MyD88-dependent IL-6 production. Science 2007;317:121-4. [PubMed: 17615358]

[10]. Harnish DC. Estrogen receptor ligands in the control of pathogenic inflammation. Curr Opin Investig Drugs 2006;7:997-1001.

[11]. Li W, Ray RM, Gao DL, Fitzgibbons ED, Seixas NS, Camp JE, et al. Occupational risk factors for nasopharyngeal cancer among female textile workers in Shanghai, China. Occup Environ Med 2006;63:39-44. [PubMed: 16361404]

[12]. Jia WH, Luo XY, Feng BJ, Ruan HL, Bei JX, Liu WS, et al. Traditional Cantonese diet and nasopharyngeal carcinoma risk: a large-scale case-control study in Guangdong, China BMC Cancer. 2010;10:446.

[13]. Xie SH, Yu IT, Tse LA, Au JS, Lau JS. Tobacco smoking, family history, and the risk of nasopharyngeal carcinoma: a case-referent study in Hong Kong Chinese. Cancer Causes Control 2015;26:913-21. [PubMed: 25822573]

[14]. Ye W, Chang ET, Liu Z, Liu Q, Cai Y, Zhang Z, et al. Development of a population-based cancer case-control study in southern china. Oncotarget 2017.

[15]. Liu Z, Scd ETC, Liu Q, Yonglin Cai MD, PhD ZZM, Chen G, et al. Quantification of familial risk of nasopharyngeal carcinoma in a high incidence area. Cancer 2017;123:2716. [PubMed: 28241094]

[16]. Liu Z, Chang ET, Liu Q, Cai Y, Zhang Z, Chen G, et al. Oral hygiene and risk of nasopharyngeal carcinoma - a population-based case-control study in China. Cancer Epidemiol Biomarkers Prev 2016;25:1201-7. [PubMed: 27197279]

[17]. Motrán CC, Díaz FL, Gruppi A, Slavin D, Chatton B, Bocco JL. Human pregnancy-specific glycoprotein 1a (PSG1a) induces alternative activation in human and mouse monocytes and 
suppresses the accessory cell-dependent $\mathrm{T}$ cell proliferation. Journal of Leukocyte Biology 2002;72:512-21. [PubMed: 12223519]

[18]. Luppi P How immune mechanisms are affected by pregnancy. Vaccine 2003;21:3352-7. [PubMed: 12850338]

[19]. Sakamoto K, Greally J, Gilfillan RF, Sexton J, Barnabei V, Yetz J, et al. Epstein-Barr virus in normal pregnant women. American Journal of Reproductive Immunology 1982;2:217. [PubMed: 6291416]

[20]. Haeri S, Baker AM, Boggess KA. Prevalence of Epstein-Barr virus reactivation in pregnancy. American Journal of Perinatology 2010;27:715-9. [PubMed: 20387188]

[21]. Meyohas MC, Maréchal V, Desire N, Bouillie J, Frottier J, Nicolas JC. Study of mother-to-child Epstein-Barr virus transmission by means of nested PCRs. Journal of Virology 1996;70:6816. [PubMed: 8794321]

[22]. Fleisher G, Bolognese R. Persistent Epstein-Barr Virus Infection and Pregnancy. Journal of Infectious Diseases 1983;147:982. [PubMed: 6304207]

[23]. Eskild A, Bruu AL, Stray-Pedersen B, Jenum P. Epstein-Barr virus infection during pregnancy and the risk of adverse pregnancy outcome. Bjog An International Journal of Obstetrics \& Gynaecology 2005;112:1620-4. [PubMed: 16305564]

[24]. Avgil M, Diav-Citrin O, Shechtman S, Arnon J, Wajnberg R, Ornoy A. Epstein-Barr virus infection in pregnancy--a prospective controlled study. Reprod Toxicol 2008;25:468-71. [PubMed: 18534816]

[25]. Xie SH, Yu IT, Tse LA, Mang OW, Yue L. Sex difference in the incidence of nasopharyngeal carcinoma in Hong Kong 1983-2008: suggestion of a potential protective role of oestrogen. Eur J Cancer 2013;49:150-5. [PubMed: 22892061]

[26]. Zhang LF, Li YH, Xie SH, Ling W, Chen SH, Liu Q, et al. Incidence trend of nasopharyngeal carcinoma from 1987 to 2011 in Sihui County, Guangdong Province, South China: an ageperiod-cohort analysis. Chin J Cancer 2015;34:350-7. [PubMed: 26058679]

[27]. Zhang Q, Jun-Qing WU, Yu-Yan LI, University F. Current Applied Situation and Influencing Factors of Oral Contraceptives in China. Reproduction \& Contraception 2014. 


\section{Highlights}

- This is the first study to assess the NPC risk associated with reproductive history;

- A history of pregnancy or delivery increased the NPC risk;

- $\quad$ NPC risk decreased with increasing time since menopause. 


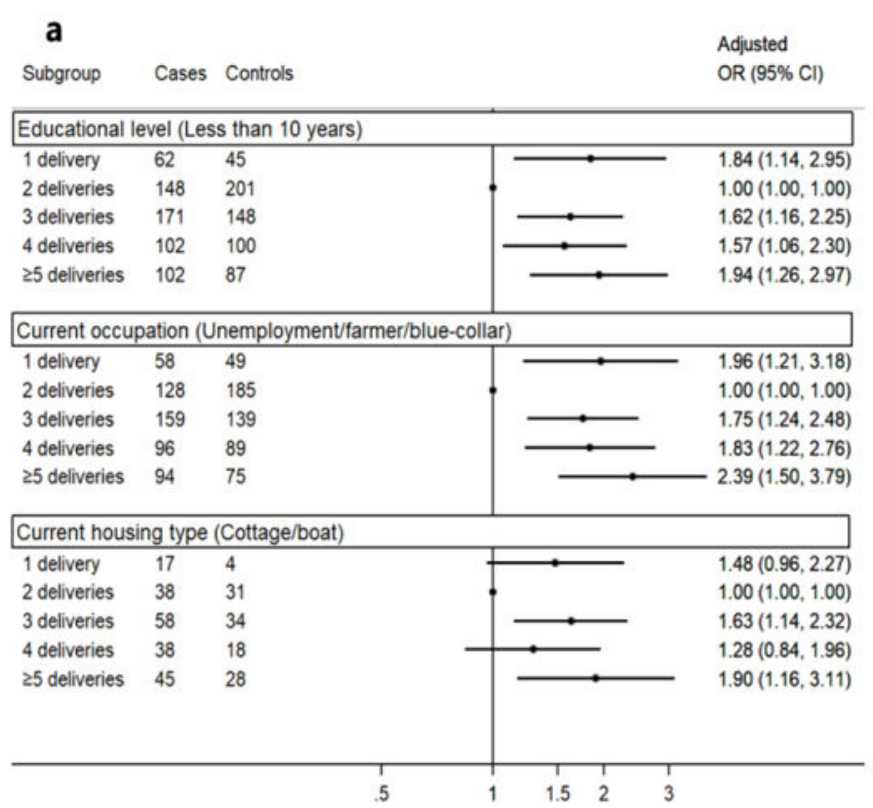

\begin{tabular}{|c|c|c|c|}
\hline b & & & Adjusted \\
\hline Subgroup & Cases & Controls & \\
\hline \multicolumn{4}{|c|}{ Educational level (More than 10 years) } \\
\hline 1 delivery & 28 & 43 & $0.87(0.36,2.11)$ \\
\hline 2 deliveries & 20 & 30 & $1.00(1.00,1.00)$ \\
\hline 3 deliveries & 10 & 9 & $2.13(0.60,7.52)$ \\
\hline 24 deliveries & 7 & 12 & $0.97(0.25,3.82)$ \\
\hline \multicolumn{4}{|c|}{ Current occupation (White-collar) } \\
\hline 1 delivery & 28 & 35 & $1.15(0.45,2.93)$ \\
\hline 2 deliveries & 22 & 30 & $1.00(1.00,1.00)$ \\
\hline 3 deliveries & 8 & 10 & $0.91(0.24,3.49)$ \\
\hline 24 deliveries & 3 & 9 & $0.34(0.06,2.06)$ \\
\hline \multicolumn{4}{|c|}{ Current housing type (Building) } \\
\hline 1 delivery & 73 & 84 & $3.98(1.05,15.11)$ \\
\hline 2 deliveries & 130 & 200 & $1.00(1.00,1.00)$ \\
\hline 3 deliveries & 123 & 123 & $1.72(0.81,3.64)$ \\
\hline 4 deliveries & 66 & 90 & $1.93(0.80,4.67)$ \\
\hline 25 deliveries & 61 & 63 & $1.92(0.81,4.51)$ \\
\hline
\end{tabular}

Figure 1. Odds ratios and $95 \%$ confidence intervals of nasopharyngeal carcinoma associated with number of deliveries, stratified by socioeconomic status indicators $\mathrm{C}$

a demonstrates results among women with disadvantaged socioeconomic status (SES), i.e. those who had less than 10 years of education, were unemployment/farmer/blue- collar workers, or resided in cottage (clay brick structure) or boat;

b shows results among women with advantaged SES, i.e. those who had more than 10 years of education, were white-collar workers, or resided in building (concrete structure). ${ }^{\mathrm{C}}$ Only among ever pregnant women, excluding two controls and two cases with no deliveries, and 13 controls and 22 cases with no pregnancies; all ORs were adjusted for age, area of residence, education level, current housing type, current occupation, current tea drinking, body mass index at age 20, salt-preserved fish consumption in 2000-2002, and nasopharyngeal carcinoma among first-degree relatives. 
Table 1.

Characteristics of 1,364 subjects, stratified by number of deliveries

\begin{tabular}{|c|c|c|c|c|c|c|}
\hline Characteristics & $\begin{array}{c}\mathbf{0} \\
\mathbf{N}=39 \\
\mathbf{N}(\%)\end{array}$ & $\begin{array}{c}1 \\
N=178 \\
N(\%)\end{array}$ & $\begin{array}{c}2 \\
\mathrm{~N}=399 \\
\mathrm{~N}(\%)\end{array}$ & $\begin{array}{c}\mathbf{3} \\
\mathbf{N}=\mathbf{3 3 8} \\
\mathbf{N}(\%)\end{array}$ & $\begin{array}{c}4 \\
\mathrm{~N}=212 \\
\mathrm{~N}(\%)\end{array}$ & $\begin{array}{c}\stackrel{25}{ } \\
N=198 \\
N(\%)\end{array}$ \\
\hline \multicolumn{7}{|l|}{ Residential area } \\
\hline Zhaoqing & $21(53.9)$ & $106(59.6)$ & $262(65.7)$ & $160(47.3)$ & $90(42.5)$ & $69(34.9)$ \\
\hline Wuzhou & $12(30.8)$ & $57(32.0)$ & $75(18.8)$ & $92(27.2)$ & $63(29.7)$ & $63(31.8)$ \\
\hline Guiping/Pingnan & $6(15.4)$ & $15(8.4)$ & $62(15.5)$ & $86(25.4)$ & $59(27.8)$ & $66(33.3)$ \\
\hline \multicolumn{7}{|l|}{ Age at interview, year } \\
\hline $20-29$ & $25(64.1)$ & $21(11.8)$ & $18(4.5)$ & $2(0.6)$ & $1(0.5)$ & $0(0.0)$ \\
\hline $30-39$ & $7(18.0)$ & $59(33.2)$ & $85(21.3)$ & $55(16.3)$ & $14(6.6)$ & $2(1.0)$ \\
\hline $40-49$ & $4(10.3)$ & $66(37.1)$ & $181(45.4)$ & $142(42.0)$ & 75 (35.4) & $46(23.2)$ \\
\hline $50-59$ & $1(2.6)$ & $30(16.9)$ & $95(23.8)$ & $82(24.3)$ & $64(30.2)$ & $57(28.8)$ \\
\hline $60-74$ & $2(5.1)$ & $2(1.1)$ & $20(5.0)$ & $57(16.9)$ & $58(27.4)$ & $93(47.0)$ \\
\hline \multicolumn{7}{|l|}{ Educational level, year } \\
\hline 0 & $1(2.6)$ & $3(1.7)$ & $23(5.8)$ & $34(10.1)$ & $34(16.0)$ & $52(26.3)$ \\
\hline $1-6$ & $8(20.5)$ & 35 (19.7) & $174(43.6)$ & $177(52.4)$ & $131(61.8)$ & $116(58.6)$ \\
\hline $7-9$ & $9(23.1)$ & $69(38.8)$ & $152(38.1)$ & $108(32)$ & 37 (17.5) & $21(10.6)$ \\
\hline$\geq 10$ & $21(53.9)$ & $71(39.9)$ & $50(12.5)$ & $19(5.6)$ & $10(4.7)$ & $9(4.6)$ \\
\hline \multicolumn{7}{|l|}{ Current housing type $\mathrm{e}^{a}$} \\
\hline Building & $34(87.2)$ & $157(88.2)$ & $330(82.7)$ & $246(72.8)$ & $156(73.6)$ & $124(62.9)$ \\
\hline Cottage/boat & $5(12.8)$ & $21(11.8)$ & $69(17.3)$ & $92(27.2)$ & $56(26.4)$ & $73(37.1)$ \\
\hline \multicolumn{7}{|l|}{ Current occupation } \\
\hline Unemployed & $2(5.1)$ & $21(11.8)$ & $42(10.5)$ & $28(8.3)$ & $16(7.6)$ & $11(5.6)$ \\
\hline Farmer & $4(10.3)$ & $21(11.8)$ & $159(39.9)$ & $193(57.1)$ & $128(60.4)$ & $144(72.7)$ \\
\hline Blue-collar & $11(28.2)$ & $65(36.5)$ & $112(28.1)$ & 77 (22.8) & $41(19.3)$ & $14(7.1)$ \\
\hline White-collar & $19(48.7)$ & $63(35.4)$ & $52(13.0)$ & $18(5.3)$ & $6(2.8)$ & $6(3.0)$ \\
\hline Other/unknown & $3(7.7)$ & $8(4.5)$ & $34(8.5)$ & $22(6.5)$ & $21(9.9)$ & $23(11.6)$ \\
\hline \multicolumn{7}{|l|}{ Cigarette smoking } \\
\hline Never & $39(100.0)$ & $176(98.9)$ & $395(99.0)$ & $328(97.0)$ & 209 (98.6) & $194(98.5)$ \\
\hline Ever & $0(0.0)$ & $2(1.1)$ & $4(1.0)$ & $10(3.0)$ & $3(1.4)$ & $3(1.5)$ \\
\hline Missing & 0 & 0 & 0 & 0 & 0 & 1 \\
\hline \multicolumn{7}{|l|}{ Current tea drinking } \\
\hline No & $39(100.0)$ & $137(77.4)$ & $331(83.2)$ & $276(81.7)$ & $179(84.4)$ & $174(88.8)$ \\
\hline Yes & $0(0.0)$ & $40(22.6)$ & $67(16.8)$ & $62(18.3)$ & $33(15.6)$ & $22(11.2)$ \\
\hline Missing & 0 & 1 & 1 & 0 & 0 & 2 \\
\hline \multicolumn{7}{|c|}{ Salt-preserved fish consumption in 2000-2002 } \\
\hline sYearly & $33(84.6)$ & $138(77.5)$ & $307(76.9)$ & $251(74.3)$ & $156(73.6)$ & $144(73.1)$ \\
\hline$\searrow$ Monthly & $6(15.4)$ & $40(22.5)$ & $92(23.1)$ & $87(25.7)$ & $56(26.4)$ & $53(26.9)$ \\
\hline Missing & 0 & 0 & 0 & 0 & 0 & 1 \\
\hline \multicolumn{7}{|c|}{ Nasopharyngeal carcinoma among first-degree relatives } \\
\hline No & $38(97.4)$ & $163(91.6)$ & $367(92.0)$ & $301(89.3)$ & $196(92.5)$ & $178(90.4)$ \\
\hline
\end{tabular}

Oral Oncol. Author manuscript; available in PMC 2020 January 01. 


\begin{tabular}{|c|c|c|c|c|c|c|}
\hline Characteristics & $\begin{array}{c}\mathbf{0} \\
\mathbf{N}=39 \\
\mathbf{N}(\%)\end{array}$ & $\begin{array}{c}1 \\
N=178 \\
N(\%)\end{array}$ & $\begin{array}{c}2 \\
N=399 \\
N(\%)\end{array}$ & $\begin{array}{c}3 \\
\mathbf{N}=\mathbf{3 3 8} \\
\mathbf{N}(\%)\end{array}$ & $\begin{array}{c}4 \\
\mathrm{~N}=212 \\
\mathrm{~N}(\%)\end{array}$ & $\begin{array}{c}\stackrel{\bullet}{+} \\
\mathbf{N}=198 \\
\mathbf{N}(\%)\end{array}$ \\
\hline Yes & $1(2.6)$ & $13(7.3)$ & $24(6.0)$ & $30(8.9)$ & $12(5.7)$ & $11(5.6)$ \\
\hline Unknown & $0(0)$ & $2(1.1)$ & $8(2.0)$ & $6(1.8)$ & $4(1.9)$ & $8(4.1)$ \\
\hline \multicolumn{7}{|c|}{ Body mass index at age $20\left(\mathrm{~kg} / \mathrm{m}^{2}\right)$} \\
\hline$<18.5$ & $7(18.0)$ & $49(27.5)$ & $68(17.0)$ & $69(20.4)$ & $38(18.0)$ & $51(25.8)$ \\
\hline $18.5-22.9$ & $28(71.8)$ & $111(62.4)$ & $273(68.4)$ & $220(65.1)$ & $139(65.9)$ & $120(60.6)$ \\
\hline$\geq 23.0$ & $4(10.3)$ & $18(10.1)$ & $58(14.5)$ & $49(14.5)$ & $34(16.1)$ & $27(13.6)$ \\
\hline Missing & 0 & 0 & 0 & 0 & 1 & 1 \\
\hline
\end{tabular}

${ }^{a}$ Current housing type included building (concrete structure), or cottage (clay brick structure) or boat. 
Table 2.

Odds ratios and corresponding 95\% confidence intervals for risk of nasopharyngeal carcinoma in association with pregnancy-related factors

\begin{tabular}{|c|c|c|c|c|}
\hline & $\begin{array}{l}\text { Cases } \\
\mathbf{N}=674 \\
\mathrm{~N}(\%)\end{array}$ & $\begin{array}{c}\text { Controls } \\
\mathbf{N}=690 \\
\mathbf{N}(\%)\end{array}$ & $\begin{array}{c}\text { Age and area } \\
\text { adjusted OR } \\
\text { (95\% CI) }\end{array}$ & $\begin{array}{c}\text { Multivariate } \\
\text { adjusted OR } \\
(95 \% \mathrm{CI})\end{array}$ \\
\hline \multicolumn{5}{|l|}{ Ever pregnant } \\
\hline Yes & $652(96.7)$ & $677(98.1)$ & 1.00 (reference) & 1.00 (reference) \\
\hline No & $22(3.3)$ & $13(1.9)$ & $1.95(0.88-4.31)$ & $2.16(0.94-4.94)$ \\
\hline \multicolumn{5}{|c|}{ No. of pregnancies ${ }^{a}$} \\
\hline 1 & $54(8.3)$ & $60(8.9)$ & $1.22(0.79-1.90)$ & $1.43(0.89-2.27)$ \\
\hline 2 & $128(19.7)$ & $182(27.0)$ & 1.00 (reference) & 1.00 (reference) \\
\hline 3 & $171(26.3)$ & $164(24.3)$ & $1.56(1.14-2.14)$ & $1.56(1.13-2.17)$ \\
\hline 4 & $121(18.6)$ & $119(17.6)$ & $1.60(1.13-2.28)$ & $1.45(1.01-2.10)$ \\
\hline 25 & $176(27.1)$ & $150(22.2)$ & $2.00(1.42-2.81)$ & $1.88(1.31-2.70)$ \\
\hline \multicolumn{5}{|l|}{ No. of deliveries ${ }^{a}$} \\
\hline 1 & $90(13.9)$ & $88(13.0)$ & $1.35(0.94-1.94)$ & $1.65(1.11-2.46)$ \\
\hline 2 & $168(25.9)$ & $231(34.2)$ & 1.00 (reference) & 1.00 (reference) \\
\hline 3 & $181(27.9)$ & $157(23.3)$ & $1.71(1.27-2.31)$ & $1.59(1.16-2.18)$ \\
\hline 4 & $104(16.0)$ & $108(16.0)$ & $1.53(1.08-2.18)$ & $1.40(0.96-2.03)$ \\
\hline 25 & $107(16.5)$ & $91(13.5)$ & $2.10(1.42-3.09)$ & $1.83(1.21-2.78)$ \\
\hline \multicolumn{5}{|c|}{ Age at first pregnancy, $y^{a}$} \\
\hline$\underline{20}$ & $86(13.2)$ & $84(12.4)$ & $1.02(0.73-1.43)$ & $0.96(0.67-1.37)$ \\
\hline $21-25$ & $390(60.0)$ & $384(56.9)$ & 1.00 (reference) & 1.00 (reference) \\
\hline $26-29$ & $152(23.4)$ & $188(27.9)$ & $0.78(0.60-1.01)$ & $0.87(0.66-1.14)$ \\
\hline$\geq 30$ & $22(3.4)$ & $19(2.8)$ & $1.11(0.59-2.08)$ & $1.19(0.62-2.28)$ \\
\hline \multicolumn{5}{|c|}{ Outcome of first pregnancy ${ }^{a}$} \\
\hline Natural delivery & $579(89.1)$ & $609(90.2)$ & 1.00 (reference) & 1.00 (reference) \\
\hline Stillbirth & $7(1.1)$ & $7(1.0)$ & $1.06(0.37-3.04)$ & $1.29(0.42-3.96)$ \\
\hline Abortion & $60(9.2)$ & $52(7.7)$ & $1.17(0.79-1.73)$ & $1.31(0.87-1.99)$ \\
\hline Other & $4(0.6)$ & $7(1.0)$ & $0.59(0.17-2.03)$ & $0.63(0.18-2.28)$ \\
\hline
\end{tabular}

Abbreviations: OR, odds ratio; 95\% CI, 95\% confidence interval.

${ }^{a}$ Only among ever pregnant women, excluding two controls and two cases with no deliveries, and 13 controls and 22 cases with no pregnancies.

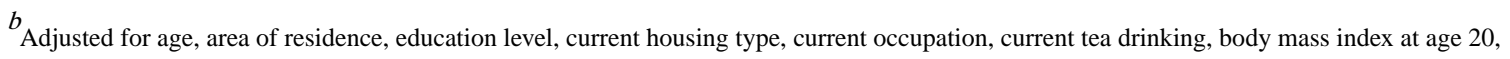
salt-preserved fish consumption in 2000-2002, and nasopharyngeal carcinoma among first-degree relatives. 
Table 3.

Odds ratios and corresponding 95\% confidence intervals for risk of nasopharyngeal carcinoma in association with menopause-related factors

\begin{tabular}{|c|c|c|c|c|}
\hline & $\begin{array}{l}\text { Cases } \\
\mathrm{N}=672 \\
\mathrm{~N}(\%)\end{array}$ & $\begin{array}{l}\text { Controls } \\
\mathbf{N}=688 \\
\mathbf{N}(\%)\end{array}$ & $\begin{array}{l}\text { Age and area } \\
\text { adjusted OR } \\
\text { (95\% CI) }\end{array}$ & $\begin{array}{c}\text { Multivariate } \\
\text { adjusted OR } \\
(95 \% \mathrm{CI})\end{array}$ \\
\hline \multicolumn{5}{|l|}{ Menopausal status } \\
\hline Pre-menopausal & $406(60.4)$ & $403(58.6)$ & 1.00 (reference) & 1.00 (reference) \\
\hline Peri/post-menopausal & $266(39.6)$ & $285(41.4)$ & $1.18(0.82-1.70)$ & $1.17(0.80-1.71)$ \\
\hline \multicolumn{5}{|c|}{ Age at menopause, year ${ }^{a}$} \\
\hline Pre-menopause & $406(60.6)$ & $403(58.6)$ & 1.00 (reference) & 1.00 (reference) \\
\hline$\$ 47$ & $79(11.8)$ & $86(12.5)$ & $1.13(0.75-1.70)$ & $1.10(0.72-1.69)$ \\
\hline $48-49$ & $49(7.3)$ & $68(9.9)$ & $0.98(0.59-1.61)$ & $0.96(0.56-1.62)$ \\
\hline $50-51$ & $74(11.0)$ & $77(11.2)$ & $1.34(0.82-2.18)$ & $1.35(0.81-2.25)$ \\
\hline$\geq 52$ & $62(9.3)$ & $54(7.9)$ & $1.62(0.96-2.73)$ & $1.67(0.96-2.89)$ \\
\hline P-trend & & & 0.068 & 0.059 \\
\hline \multicolumn{5}{|c|}{ Time since menopause, year $b$} \\
\hline $0-3$ & $80(30.3)$ & $70(24.6)$ & 1.00 (reference) & 1.00 (reference) \\
\hline $4-9$ & $75(28.4)$ & $68(23.9)$ & $0.87(0.53-1.42)$ & $0.81(0.47-1.38)$ \\
\hline $10-14$ & $65(24.6)$ & $70(24.6)$ & $0.69(0.37-1.26)$ & $0.67(0.35-1.29)$ \\
\hline$\geq 15$ & $44(16.7)$ & $77(27.0)$ & $0.41(0.20-0.84)$ & $0.35(0.16-0.75)$ \\
\hline$P$-trend & & & 0.017 & 0.010 \\
\hline
\end{tabular}

Abbreviations: OR, odds ratio; 95\% CI, 95\% confidence interval.

${ }^{a}$ Age at menopause for two cases was missing.

${ }^{b}$ Among peri-/postmenopausal women (N=549).

${ }^{c}$ Adjusted for age, area of residence, education level, current housing type, current occupation, current tea drinking, body mass index at age 20, salt-preserved fish consumption in 2000-2002, and nasopharyngeal carcinoma among first-degree relatives. 
Table 4.

Odds ratios and corresponding 95\% confidence intervals for risk of nasopharyngeal carcinoma in association with number of pregnancies or deliveries, stratified by age at diagnosis/interview

\begin{tabular}{|c|c|c|c|c|c|c|}
\hline \multicolumn{4}{|c|}{$<50$ years } & \multicolumn{3}{|c|}{50 years } \\
\hline & $\begin{array}{l}\text { Cases } \\
\mathbf{N}=387 \\
\mathbf{N}(\%)\end{array}$ & $\begin{array}{c}\text { Controls } \\
\mathbf{N}=\mathbf{3 8 0} \\
\mathbf{N}(\%)\end{array}$ & $\begin{array}{c}\text { Multivariate } \\
\text { adjusted OR } \\
(95 \% \text { CI })\end{array}$ & $\begin{array}{l}\text { Cases } \\
\mathrm{N}=263 \\
\mathrm{~N}(\%)\end{array}$ & $\begin{array}{c}\text { Controls } \\
\mathbf{N}=295 \\
\mathbf{N}(\%)\end{array}$ & $\begin{array}{c}\text { Multivariate } \\
\text { adjusted OR } \\
(95 \% \mathrm{CI})\end{array}$ \\
\hline \multicolumn{7}{|c|}{ No. of pregnancies ${ }^{a}$} \\
\hline 1 & $49(12.7)$ & 48 (12.6) & $1.98(1.17-3.37)$ & $5(1.9)$ & $12(4.1)$ & $0.51(0.16-1.64)$ \\
\hline 2 & $83(21.5)$ & $132(34.7)$ & 1.00 (reference) & $45(17.1)$ & $50(17.0)$ & 1.00 (reference) \\
\hline 3 & $115(29.7)$ & $98(25.8)$ & $2.00(1.33-3.00)$ & $56(21.3)$ & $66(22.4)$ & $0.85(0.48-1.49)$ \\
\hline 4 & 68 (17.6) & $51(13.4)$ & $1.89(1.16-3.07)$ & $53(20.2)$ & $68(23.1)$ & $0.78(0.43-1.41)$ \\
\hline 25 & $72(18.6)$ & $51(13.4)$ & $2.15(1.32-3.50)$ & $104(39.5)$ & 99 (33.6) & $1.04(0.60-1.82)$ \\
\hline \multicolumn{7}{|c|}{ No. of deliveries ${ }^{a}$} \\
\hline 1 & $73(18.9)$ & $73(19.2)$ & $1.67(1.07-2.61)$ & $17(6.5)$ & $15(5.1)$ & $2.04(0.83-5.01)$ \\
\hline 2 & $120(31.0)$ & $164(43.2)$ & 1.00 (reference) & $48(18.3)$ & 67 (22.7) & 1.00 (reference) \\
\hline 3 & $114(29.5)$ & $85(22.4)$ & $1.76(1.18-2.61)$ & $67(25.5)$ & $72(24.4)$ & $1.14(0.67-1.95)$ \\
\hline 4 & $50(12.9)$ & $40(10.5)$ & $1.51(0.90-2.51)$ & $54(20.5)$ & $68(23.1)$ & $1.05(0.60-1.86)$ \\
\hline 25 & $30(7.8)$ & $18(4.7)$ & $1.93(0.98-3.77)$ & 77 (29.3) & $73(24.8)$ & $1.29(0.73-2.29)$ \\
\hline
\end{tabular}

Abbreviations: OR, odds ratio; 95\% CI, 95\% confidence interval.

${ }^{a}$ Only women with ever pregnancy, excluding two controls and two cases with no deliveries, and 13 controls and 22 cases with no pregnancies.$$
b
$$

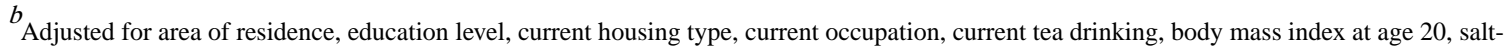
preserved fish consumption in 2000-2002, and nasopharyngeal carcinoma among first-degree relatives. 